\title{
Rheumatoid factors: where are we now?
}

Rheumatoid factors (RFs) are autoantibodies against IgG. They are probably the most studied antibody since their discovery by Waaler in 1937. In this editorial we aim to briefly examine the proposed roles of RFs, how they may contribute to disease pathogenicity, and, in so doing, mention the application of novel peptide technology, crystallography and molecular modelling to rheumatoid factor study.

\section{Occurrence and roles of rheumatoid factors}

RFs are not exclusive to rheumatoid arthritis (RA). They are found in a number of other autoimmune diseases, such as systemic lupus erythematous and Sjögren's syndrome, infectious diseases such a mycobacterium tuberculosis, and Lyme disease and in healthy people. ${ }^{1}$

RFs seem to have a beneficial role to the normal functioning of the immune system. They may do this in a number of ways:

(1) Clearance of immune complexes. IgM and IgG RFs may bind to an antibody-antigen complex and facilitate clearance by binding to the $\mathrm{Fc}_{\mathrm{c}}$ receptors on phagocytes. ${ }^{2}$ In particular, this may facilitate clearance of IgG2 and IgG4 immune complexes as these subclasses do not readily activate complement.

(2) Antigen processing by B cells. B cells can act as antigen presenting cells as they can use their surface immunoglobulin to capture antigen. Membrane bound RFs can therefore capture immune complexes containing IgG that can then be internalised, which may lead to the presentation of a relevant epitope to a $\mathrm{T}$ cell as part of an immune response. ${ }^{23}$

(3) Setting up an early antibody repertoire. Antibodies that behave as RFs can be found in human fetal liver and spleen, ${ }^{45}$ which suggests that autoreactive $B$ cells are playing a part in the development of a functional antibody repertoire.

\section{How can rheumatoid factors contribute to disease pathogenesis?}

$\mathrm{RF}$ involvement in immune complex formation may lead to fixation of complement and recruitment of macrophages, neutrophils, and lymphocytes. Such involvement may be one part of an autoimmune inflammatory response that results in arthritis.

So how can RFs on the one hand be beneficial while on the other be potentially pathogenic? One clue we have is that naturally occurring RFs are mainly of the $\operatorname{IgM}$ isotype, while IgG RFs are thought to be associated with disease. It is probable that the production of pathogenic RFs are dependent on a class switch of antibody from IgM to IgG. This would imply that $T$ cell help is available as the switch from IgM to IgG is usually under $\mathrm{T}$ helper cell control. This leads us to question 'what are the antigenic peptides that activate $T$ cells and allow them to help B cells produce IgG RFs?'. Identifying such a peptide trigger has been elusive. It may be that one has to look at peptides from IgG itself or even RFs. In support of this notion, there are data to suggest that $\kappa I I I b$ light chains from RFs can cause $T$ cell proliferation (J Petersen et al, 7th international conference on immunology, 1989).

\section{The mechanism of rheumatoid factor binding to IgG}

There is at least $6 \mathrm{mg} / \mathrm{ml}$ of $\mathrm{IgG}$ in the serum and only 3 $\mathrm{mg} / \mathrm{ml}$ of IgM. If all this were RF, which is unlikely, it is surprising that we can detect free $\mathrm{RF}$ at all in such an excess of IgG antigen. This suggests that either some RFs do not bind to certain types of IgG or that not all IgG is of a type that is capable of being bound by RFs.

The site of binding for many RFs is thought to lie at the C $\gamma 2-\mathrm{C} \gamma 3$ domain interface in Fc, based upon evidence from serology, human subclass reactivity patterns, and more recently, site directed mutagenesis. ${ }^{6}$ The last approach has identified key determinants in discontinuous loop regions of $C \gamma 2$ and $C \gamma 3$. Yet it is not known whether pathogenic and non-pathogenic RFs bind to similar or separate sites on the IgG molecules.

It is known that in RA IgG oligosaccharides change such that there is a shift to the agalactosylated form, ${ }^{7}$ which may uncover novel peptide epitopes and hence facilitate RF binding. Using monoclonal RFs from synovial tissue, it has recently been demonstrated that in some instances the binding is greatly increased when galactose is absent. ${ }^{8}$ These same RFs had at least 10 times higher affinity for human $\mathrm{IgG}^{9}$ than those monoclonal RFs that bound independently of sugar.

The work of Hay and others have suggested that there may be several mechanisms for RF binding. ${ }^{10}$

(1) Binding to continuous or discontinuous determinants on IgG away from the influence of oligosaccharides. ${ }^{11}$

(2) Binding to peptides that have been uncovered by the absence of oligosaccharide or made available for interaction because of conformational change resulting from oligosaccharide absence. ${ }^{12}$

(3) Binding to IgG via RF framework peptides away from the conventional complementarity determining regions. ${ }^{13-15}$

The structure of the first complex between a RF and IgG $F c$ has now been determined by $x$ ray crystallography ${ }^{16} 17$ and it shows the RF Fab fragment binding through its complementarity determining regions to an epitope on the IgG Fc that spans the $\mathrm{C} \gamma 2$ and $\mathrm{C} \gamma 3$ domains (see fig 1). The RF in this study (RF-AN) is derived from the peripheral $B$ cell of an RA patient ${ }^{18}$ and is an $\operatorname{IgM} / \lambda$ antibody with a pattern of reactivity with human subclasses IgG 1,2 , and 4 that is typical of many RFs and mirrors that of the bacterial Fc-binding protein A. The binding site for protein A lies in the cleft between the two domains, ${ }^{19}$ and this RF clearly overlaps this area. The human IgG4 Fc present in the complex is predominantly agalactosyl, ${ }^{1620}$ similar to that found in the immune complexes of RA patients. However, for this particular RF, the carbohydrate itself does not seem to be involved in RF recognition of Fc.

It is now important to study the structures of the complexes formed by other higher affinity RFs, and of the IgG class, to compare the modes of interaction, the nature of the epitopes recognised, and the role of the oligosaccharides. It may then be possible to identify the structural features that distinguish the pathogenic from the non-pathogenic RFs.

Our further understanding of the mechanisms of RF binding may be diagnostically helpful if pathogenic RFs can be differentiated between those that are harmless. It would also open up a number of further options whereby the RF binding mechanisms could be interrupted.

\section{Conclusion}

It is clear that RFs are more than markers of RA and dissecting out their physiological role and how they may be involved in pathological mechanisms will be exciting. Crystallographic analysis and molecular modelling of both 


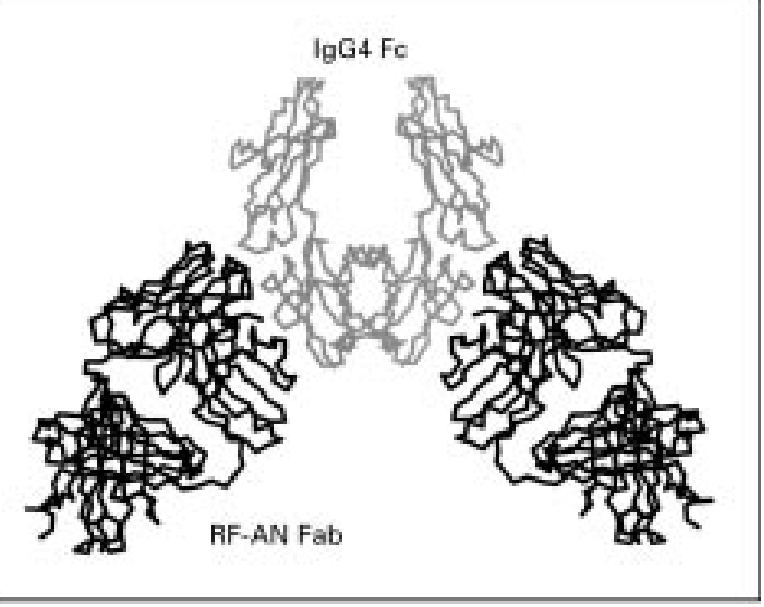

Figure 1 Diagramatic representation of rheumatoid factor AN Fab fragment binding to an epitope in $\operatorname{Ig} G F_{C}$ that spans the $C \gamma 2$ and $C \gamma 3$ domains as determined by $x$ ray crystallography.

polypeptide and oligosaccharide structures will undoubtedly aid this process, and epitope mapping has also been shown to be a powerful tool. Whether new diagnostics and novel therapeutic interventions will result remains to be seen, let us hope so, but hopefully we will not have to wait another 50 years for the answer.

A J SOLTYS

J S AXFORD

Academic Rheumatology Unit, St George's Hospital Medical School, London

The Randall Institute, King's College London

B J SUTTON

Correspondence to: Dr J S Axford, Academic Rheumatology Unit, St George's Hospital Medical School, Cranmer Terrace, London SW 17 ORE.

1 Carson DA, Chen PP, Fox RI, Kipps TJ, Jirik F, Goldfien RD, et al. Rheumatoid factor and immune networks. Ann Rev Immunol 1987;5:109-26. 2 Carson DA, Chen PP, Kipps TJ. New roles for rheumatoid factor.[Review]. J Clin Invest 1991;87:379-83.

3 Roosnek E, Lanzavecchia A. Efficient and selective presentation of antigenantibody complexes by rheumatoid factor B cells. J Exp Med 1991;173:487-9.
4 Kipps TJ, Robbins BA, Carson DA. Uniform high frequency expression of autoantibody-associated crossreactive idiotypes in the primary B cell folliautoantibody-associated crossreactive idiotypes in the pri
cles of human fetal spleen. J Exp Med 1990;171:189-96.

5 Schroeder HJ, Hillson JL, Perlmutter RM. Early restriction of the human antibody repertoire. Science 1987;238:791-3.

6 Artandi SE, Calame KL, Morrison SL, Bonagura VR. Monoclonal IgM rheumatoid factors bind IgG at a discontinuous epitope comprised of amino acid loops from heavy-chain constant-region domains 2 and 3. Proc Natl Acad Sci USA 1992;89:94-8.

7 Parekh RB, Dwek RA, Sutton BJ, Fernandes DL, Leung A, Stanworth D, et al. Association of rheumatoid arthritis and primary osteoarthritis with changes in the glycosylation pattern of total serum IgG. Nature 1985;316:452-7.

8 Soltys AJ, Hay FC, Bond A, Axford JS, Jones MG, Randen, et al. The binding of synovial tissue-derived human monoclonal immunoglobulin $M$ rheumatoid factor to immunoglobulin $G$ preparations of differing galactose content. Scand J Immunol 1994;40:135-43.

9 Randen I, Brown D, Thompson KM, Hughes-Jones N, Pascual V, Victor K, et al. Clonally related IgM rheumatoid factors undergo affinity maturation in the rheumatoid synovial tissue. J Immunol 1992;148:3296-301.

10 Hay FC, Jones MG, Bond A, Soltys AJ. Rheumatoid factors and complex formation. The role of light-chain framework sequences and glycosylation. Hahn B, ed. Clin Orth \& Related Res. Newest Knowledge in Rheumatoid Arthritis 1991;265:54-62

11 Soltys AJ, Westwood OMR, Austen BM, Bond A, Hay FC. Analysis of rheumatoid factor binding to synthetic peptides and galactose deficient IgG molecules. [Abstract.] Clin Exp Rheumatol 1994;12:110.

12 Westwood OMR, Soltys AJ, Austen BM, Hay FC. Molecular modelling of IgG $\mathrm{Fc}$ reveals clustering of linear sequence to form potential conformational epitopes for binding rheumatoid factors. [Abstract] Clin Exp Rheumatol 1994;12:110.

13 Hay FC, Soltys AJ, Tribbick G, Geysen HM. Framework peptides from kappa IIIb rheumatoid factor light chains with binding activity for aggregated IgG. Eur J Immunol 1991;21:1837-41.

14 Shlomchik M, Nemazee D, van SJ, Weigert $M$. Variable region sequences of murine IgM anti-IgG monoclonal autoantibodies (rheumatoid factors). II. Comparison of hybridomas derived by lipopolysaccharide stimulation and secondary protein immunization. J Exp Med 1987;165:970-87.

15 Chen PP, Robbins DL, Jirik FR, Kipps TJ, Carson DA. Isolation and characterization of a light chain variable region gene for human rheumatoid factors. J Exp Med 1987;166:1900-5.

16 Sohi MK, Corper AL, Wan T, Steinitz M, Jefferis R, Beale D, et al. Crystallisation of a complex between the Fab fragment of a human immunoglobulin $M$ (IgM) rheumatoid factor (RF-AN) and the Fc fragment of human IgG4. Immunology 1996;88;636-41.

17 Cooper AL, Sohi MK, Bonagura VR, Steinitz M, Jeffries R, Feinstein A, et al. Structure of a human IgM rheumatoid factor Fab bound to its auto antigen IgG Fc reveals a novel topology of antibody-antigen interaction. Nat Struct Biol (in press).

18 Steinitz M, Izak G, Cohen S, Ehrenfeld M, Flechner J. Continuous production of monoclonal rheumatoid factor by EBV-transformed lymphocytes. Nature 1980;287:443-5.

19 Deisenhofer J. Crystallographic refinement and atomic models of a human Fc fragment and its complex with fragment B of protein A from Staphylococcus aureus at 2.9 and 2.8 angstrom resolution. Biochemistry 1981;20:2360.

20 Jefferis R, Lund J, Mizutani H, Nakagawa H, Kawazoe Y, Arata Y, et al. A comparative study of the N-linked oligosaccharide structures of human IgG sub-class proteins. Biochem J 1990; 268:529-37. 